\title{
A POTENTIALLY PREVENTABLE FATAL OUTCOME IN A PATIENT WHO DEVELOPED CEREBRAL MALARIA
}

\author{
Vidanapathirana $M .^{1}$, Munasinghe K.R. ${ }^{2}$, Benaragama D.H. ${ }^{3}$ \\ ${ }^{1}$ Senior Lecturer, Department of Forensic Medicine, ${ }^{3}$ Senior lecturer, Department of Pathology, \\ Faculty of Medical Sciences, University of Sri Jayewardenepura, Sri Lanka. \\ ${ }^{2}$ Registrar, Office of the JMO, Teaching Hospital Karapitiya, Sri Lanka.
}

\section{INTRODUCTION}

The incidence of malaria in Sri Lanka has reduced significantly due to the effective prevention programme to eradicate malaria by 2014. Only 124 new cases were found in $2011^{1}$. Early identification, treatment and effective follow up are the main targets of achieving this goal. Malaria was the most commonly diagnosed disease among tourists staying for a short period in endemic areas of tropical countries ${ }^{2}$.

\section{Case report}

A 34 year old male presented with fever after returning from India following one month stay without anti-malarial prophylaxis. Four days after return to Sri Lanka, he developed fever with chills and rigors. On the $3^{\text {rd }}$ day of fever, he was admitted to a tertiary care hospital with headache, dizziness and mild cough.

On admission, his urine output was low and the colour was dark. He had splenomegaly and cervical lymphadenopathy. He did not have bleeding tendency or neck stiffness. Although the diagnosis of malaria was suspected, antimalarial treatment was not commenced as his fever spikes settled a few hours after the admission.

He developed mild fever on the day 2 of admission and investigations showed WBC 14,500 (Neutrophil 80\%, Lymphocytes 14\%,
Eosinophils 2\%), Hb $16.5 \mathrm{~g} / \mathrm{dl}, \mathrm{PCV}$ was $51 \%$ and platelet count was $190,000 / \mathrm{mm} 3$. SAT was negative. His blood picture was negative for malaria parasites and he was discharged by the on-call physician at noon. Before leaving hospital he developed bradycardia, sweating and palpitation. In the evening, he developed a seizure and progressed to loss of consciousness with brisk lower limb reflexes.

A diagnosis of cerebral malaria or intracerebral haemorrhage due to dengue was suspected and IV quinine, dexamethasone and antibiotics were given in the intensive care unit. CT brain was not done. Approximately 30 hours after admission, he died In spite of intensive care treatment.

At autopsy there was froth from nose and mouth with severe pulmonary oedema. He had splenomegaly $(400 \mathrm{~g})$ and fatty liver $(2 \mathrm{~kg})$. Also he had severe cerebral oedema with focal haemorrhages.

Histopathology of liver (photomicrograph 01) and spleen (photomicrograph 02) showed brown-black pigment in the RBCs and macrophages. The brain showed cerebral oedema. Blood vessels of the brain were filled with parasitized RBC containing malarial pigment and pigment was also found in brain tissue (Photomicrograph 03). The cause of death was given as compatible with cerebral malaria. 


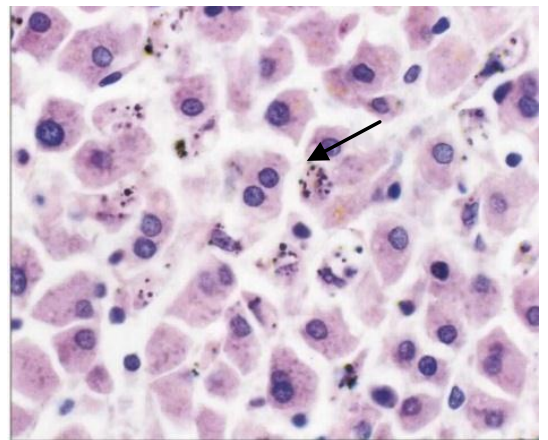

Photomicrograph 01- Malarial pigments in hepatocytes (arrow) (H and E stain $x$ 40)

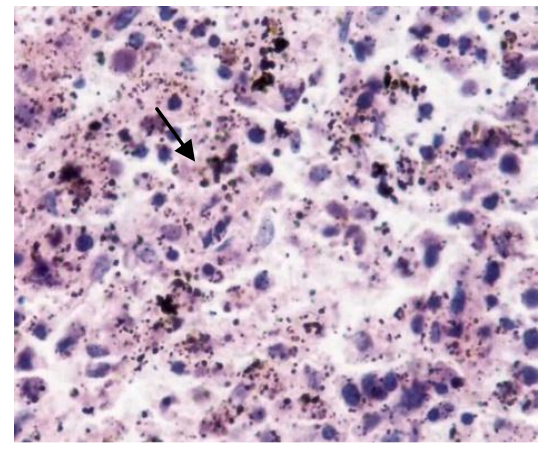

Photomicrograph 02- Malarial pigment in splenic macrophages (arrow). (H and E stain $x 40$ )

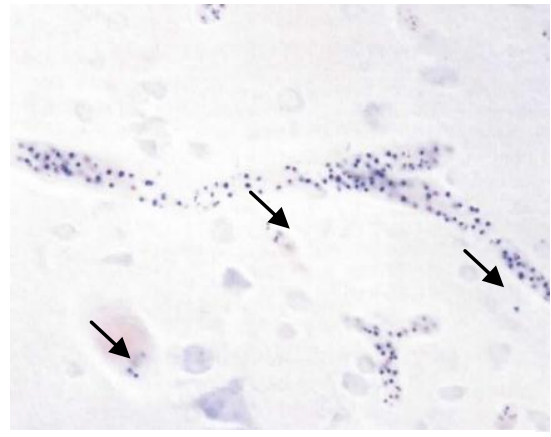

Photomicrograph 03 - Cerebral oedema with occlusion of blood vessels by parasitized RBCs. Pigment was found (arrows) within brain tissue also ( $H$ and $E$ stain $x$ 40)

\section{DISCUSSION}

Malaria is still the cause of death more than any other communicable diseases except tuberculosis ${ }^{2}$. Adhesion of parasitized RBCs to vascular endothelium results in an immune mediated response and haemostatic derangements. Injury to the endothelial cells of the cerebral vessels results in subsequent breakdown in blood brain barrier. Therefore, this is a complex multi-system disorder and causes parallel dysfunction of other organs ${ }^{2}$.

Most common causes of splenomegaly include infectious mononucleosis, leukaemia and malaria $^{3}$. Fever with chills and rigors and a palpable large spleen on admission were suggestive of malaria. Absence of fever spikes within the initial few hours of admission could have delayed in commencing anti-malarial treatment.

The 'diagnosis of malaria' is made in the presence of asexual forms of $\mathrm{P}$. falciparum in the peripheral blood smears ${ }^{4}$. The decision to discharge the patient on the next day noon may have been due to the absence of malarial parasites in the peripheral blood, absence of fever spikes and the negative SAT. Although a higher density of parasites appear in circulation during fever paroxysms, it is important that blood films are obtained several times daily and for several days to identify parasites in patients with low density infections, and a single negative blood picture do not preclude the diagnosis of malaria or cerebral involvement ${ }^{5}$.
Further, when more than one physician is involved in the management, it is important to obtain the views of the other physicians before discharging the patient, especially if there is history of travel to malaria endemic areas.

The patient was a febrile at the time of the discharge. Though sudden deterioration of an already discharged patient is rare, such circumstances are reported ${ }^{6}$. Features such as rigidity of limbs and frothing were suggestive of an episode of seizure. Despite delay, the clinicians started a loading dose of IV quinine as treatment of cerebral malaria pending a CT brain to exclude natural or traumatic Intracerebral haemorrhage. The clinical criteria of diagnosis of cerebral malaria include unarousable coma, exclusion of other encephalopathies and the confirmation of $\mathrm{P}$. falciparum infection ${ }^{5}$. For confirmation of $P$. falciparum, parasite must be demonstrated in peripheral blood smear or bone marrow smear during life or in a brain smear after death ${ }^{6}$. This patient had seizures and coma but the blood picture was not positive for malaria.

Froth at nose and mouth at autopsy further corroborated the possible episode of a seizure at terminal stages. Although splenomegaly and inguinal lymphadenopathy were found, diseases such as IMN, haematological malignancies, etc were excluded due to the absence of supportive clinical and laboratory findings. However, presence of malarial pigment in liver and spleen on microscopic examination (photomicrographs 01 and 02 ) was compatible with a diagnosis of malaria. 
Cerebral malaria occurs when Plasmodium falciparum parasitizes large numbers of RBCs, and the capillaries in the brain become blocked by agglutinated masses of parasite-containing $\mathrm{RBCs}^{7}$. Further, there is haemorrhage around the blocked vessels. Small necrotic and haemorrhagic foci can be seen within the cortex of the cerebrum and cerebellum, and in the cerebellar hemispheres and peduncles. The brain vessels are plugged with parasitized RBC, each containing dots of haemozoin malarial pigment ${ }^{7}$. The focal haemorrhages around vessels, are probably related to local hypoxia due to the vascular stasis and focal inflammatory reactions (Durck's granulomas) ${ }^{7}$. With severe hypoxia, there is degeneration of neurones, focal ischaemic softening and occasionally scanty inflammatory infiltrates in the meninges ${ }^{8}$. Blockage of small vessels of the brain by parasitized RBCs is a particularly important feature of cerebral malaria, a serious and often fatal condition'. The malaria parasite appears as small basophilic 'rings',

In this case, the presence of clinical findings, seizure attack, autopsy evidence of massive cerebral oedema and focal haemorrhages in the brain with histological evidence of cerebral oedema, occlusion of the cerebral vessels with parasitized RBC containing pigments and finding of pigment within the brain tissue outside the blood vessels were supportive of cerebral malaria.

In the absence of a vaccine, the quick and accurate diagnosis of malaria, early treatment and proper management are the only effective ways of controlling mortality due to $P$. falciparum $^{\mathbf{1 0}}$. This death could have been prevented, if the disease was suspected and treatment was commenced at the initial stage. This case was reported to the inquirer into sudden deaths as a potential case of medical negligence. Therefore, it is important to consider malaria on a possible cause of death in sudden unexpected death in adults.

\section{REFERENCES}

1. Abeyasinghe RR, Galappaththy GN, Smith Gueye C, Kahn JG, Feachem RG. Malaria control and elimination in Sri Lanka: documenting progress and success factors in a conflict setting. PLoS One. 2012;7(8).e43162. doi: 10.1371 / journal. pone. 0043162. Epub (accessed 28.12.2013)

2. Gay F, Zougbédé S, N'dilimabaka N, Rebollo A, Mazier D, Moreno A. Cerebral malaria: what is known and what is on research. Rev Neurol (Paris). 2012;Mar;168(3):239-56.

3. DiMaio VJ, DiMaio D. blunt trauma injuries of the trunk and extremities, spleen. Forensic Pathology, $2^{\text {nd }}$ Ed, Boca Raton, Florida: CRC press, 2001:135

4. WHO malaria action programme, Severe and Complicated Malaria. Trans R Soc Trop Med Hyg 1986;80 Suppl:3-50

5. Wyler D J: Plasmodium Species (Malaria). In: Mandell GL, Douglas RG, Bennett JE, eds. Principles and Practice of Infectious Diseases. New York: Churchill Livingstone, 1990:2056-66

6. Schmutxhard E. Cerebral malaria: clinical features and diagnosis. The African Journal of Neurological Sciences , 1998; Vol 17 No.1

7. Curren R, Jones EL. Gross pathology, Harvey miller:Oxford University Press, 1974:78

8. Cortran RS, Kumar V, Robbins SL, Robbins pathologic basis of disease, $5^{\text {th }}$ Ed, USA: WB Saunders company, 1994:363

9. Curren RC. Colour atlas of histopathology, $3^{\text {rd }} \mathrm{Ed}$, Harvey miller publishers, New York: oxford university press, 1995:155

10. Kalinowska-Nowak A, Bociaga-Jasik M, Leśniak M, Mach T, Garlicki A. The risk of malaria during travel, observations in the department of infectious diseases in Cracow from 1996 to 2010, Przegl Epidemiol. 2012;66(3):431-6. 